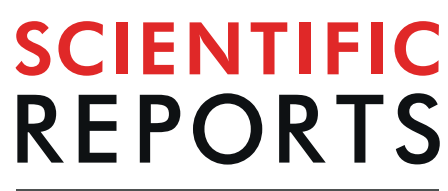

natureresearch

Received: 19 June 2019

Accepted: 20 September 2019

Published online: 07 October 2019

\section{A Novel Optical Method To Reversibly Control Enzymatic Activity Based On Photoacids}

\author{
Heike Kagel $\mathbb{B}^{1}{ }^{1}$, Frank F. Bier ${ }^{2}$, Marcus Frohme ${ }^{1}$ \& Jörn F. Glökler $\mathbb{B}^{1}$
}

Most biochemical reactions depend on the $\mathrm{pH}$ value of the aqueous environment and some are strongly favoured to occur in an acidic environment. A non-invasive control of $\mathrm{pH}$ to tightly regulate such reactions with defined start and end points is a highly desirable feature in certain applications, but has proven difficult to achieve so far. We report a novel optical approach to reversibly control a typical biochemical reaction by changing the $\mathrm{pH}$ and using acid phosphatase as a model enzyme. The reversible photoacid G-acid functions as a proton donor, changing the $\mathrm{pH}$ rapidly and reversibly by using high power UV LEDs as an illumination source in our experimental setup. The reaction can be tightly controlled by simply switching the light on and off and should be applicable to a wide range of other enzymatic reactions, thus enabling miniaturization and parallelization through non-invasive optical means.

Enzymatic reactions can occur spontaneously provided that sufficient amount of substrate is available and no otherwise inhibiting conditions are present. In many settings, such as enzyme kinetic measurements, it is desired to control at least the starting point of the reaction. Generally, this can be achieved by adding the enzyme or substrate, but this is not applicable to assays in which many reactions are to be monitored in parallel or when the handling would require opening and closing of tubes, potentially resulting in a less reproducible assay. In addition, it is also useful to stop the reaction at a defined point in order to correctly measure the end point as well.

Thus, it would be highly desirable to initiate and stop such reactions in a non-invasive manner. Typical non-invasive means to control enzymatic reactions are temperature change and irradiation. The former is mostly applicable to reactions that occur at more extreme temperature points involving thermophilic enzymes. The latter requires a receptor or transducer that responds to the radiation in a defined manner. This receptor can either be the enzyme in the biochemical reaction itself $\mathrm{f}^{1-3}$, the substrate $\mathrm{t}^{4,5}$ or inhibitor ${ }^{6-8}$. Especially engineering of proteins to become photoresponsive is very difficult to achieve and not applicable to all enzymes, therefor optical control of substrate or inhibitor may represent a more simple alternative. For instance, photocaged reagents can be simply deprotected by a light source. However, this often requires a longer time period in which the deprotection occurs and thus undesirably delays the start of the enzymatical reaction. A more general alternative is the use of a transducer that directly influences the properties of the reaction environment. Many biochemical reactions occur in specific compartments under defined environmental conditions. For example, lysosomes are cellular compartments in which hydrolytic reactions occur that are strongly accelerated under acidic conditions 9 . Therefore, many hydrolytic biochemical reactions should be controllable if the $\mathrm{pH}$ can be changed by optical means. A recent publication has explored the concept of "photoswitching" of enzyme activity by a transducer that changes the environment of the reaction ${ }^{10}$. In this case, a photoacid generator (PAG) is used as the radiation-responsive transducer and acid phosphatase (AP) as a model pH-dependent hydrolytic enzyme. As the PAG 2-nitrobenzaldehyde can be rapidly triggered by irradiation, the $\mathrm{pH}$ is strongly decreased, thereby activating the acid phosphatase. However, the conversion of the photoacid generator is irreversible and cannot be used to stop the reaction once it has been started. Thus, it would be advantageous to employ a reversible radiation-responsive transducer in order to enable optical control of the enzymatic reaction by $\mathrm{pH}$ change over the entire time course in a non-invasive manner. We have identified a reversible photoacid (PA) as a potential radiation-responsive transducer that is able to change the environmental $\mathrm{pH}$. In contrast to a PAG used by Kohse et al., a reversible photoacid is not structurally disintegrated upon illumination, but can recombine with a proton after returning to the ground state. Very common families of photoacids comprise phenol, naphthol and pyrene derivatives. The most defining feature for

${ }^{1}$ Technical University of Applied Sciences, Department of Molecular Biology and Functional Genomics, Hochschulring 1, Wildau, 15745, Germany. ${ }^{2}$ Potsdam University, Institute for Biochemistry and Biology, Karl-Liebknecht-Str. 2425, Potsdam, 14476, Germany. Correspondence and requests for materials should be addressed to M.F. (email: mfrohme@th-wildau.de) 


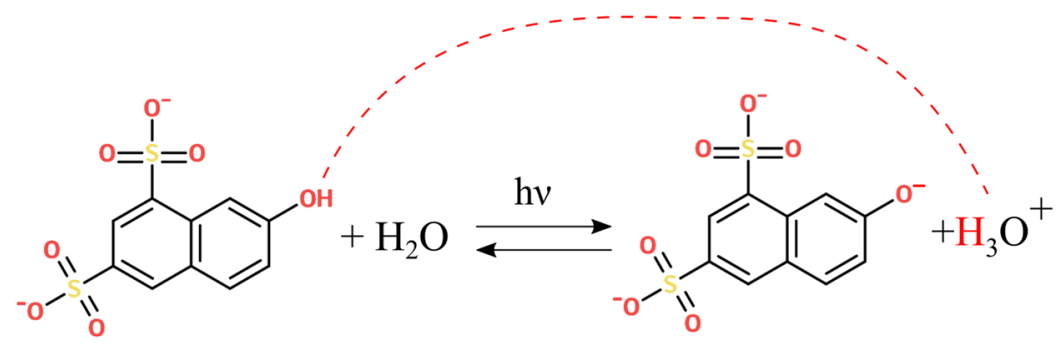

Figure 1. Reversible, light-induced mechanism of G-acid deprotonation.

all reversible photo acids is a functional group that donates the proton in an excited state proton transfer (ESPT) process ${ }^{11}$. Depending on various factors the photo-released proton can diffuse and escape the zone of influence of the parent ion, enabling it to react with the surrounding environment. It is also possible that it is re-captured by the parent ion after returning to the ground state S0. The dissociation can be induced by a laser pulse, converting a weak acid into a strong acid ${ }^{12,13}$. This process may occur rapidly within mere pico- to nanoseconds. We employed the photoacid 2-Naphthol-6, 8-disulfonic acid (G-acid) belonging to the family of naphthol derivatives, which is well soluble in water and has a low toxicity. The mechanism of G-acid deprotonation has been well established ${ }^{11,14,15}$ (See Fig. 1).

An optically triggered $\mathrm{pH}$ change was demonstrated to occur in a virtually instantaneous manner within nanoseconds ${ }^{16,17}$. It was shown that aqueous solutions could be acidified on a microsecond scale by exciting the photoacids HPTS and G-acid, using a short $347.2 \mathrm{~nm}$ laser pulse of $50 \mathrm{~ns}$. Despite having been extensively used to study ESPT, the application of PAs in biochemistry and biology are still very scarce, reviewed in ${ }^{18}$. In order to use a photoacid in a wide range of biochemical applications it must meet certain requirements: It should be soluble in water, have a low toxicity and excitable with commonly available, inexpensive illumination sources, such as LEDs. LEDs have several advantages compared to more conventional illumination sources: They are more efficient, have a long life time, a compact size, and high reliability ${ }^{19}$. Furthermore, they can be easily obtained and the mounting is significantly less complex than that of laser systems. Furthermore, we have chosen an acid phosphatase as a model enzyme. The activity optimum of APs typically lies at an acidic $\mathrm{pH}$ of $4.5-5.5^{20}$. APs non-specifically catalyze the hydrolysis of e.g. monoesters to produce inorganic phosphate under acidic conditions ${ }^{21}$. More specifically, the acid phosphatase from potato (EC 3.1.3.2) used in our experiments is active between $\mathrm{pH} 4-7^{22}$, with an activity optimum at a $\mathrm{pH}$ of $5-5.3^{20,23}$. At an alkaline $\mathrm{pH}$ of 8 the activity is several orders of magnitude lower ${ }^{10}$. A standard absorption assay to determine AP's activity is the p-nitrophenyl phosphate (pNPP) assay ${ }^{24}$. The pNPP assay is a colorimetric assay. The substrate $\mathrm{pNPP}$ is hydrolyzed by acid phosphatase into the product p-nitrophenol $(\mathrm{pNP})+\mathrm{Pi}$ in purified HPLC grade water:

$$
p N P P \stackrel{\text { Acid Phosphatase }}{\longrightarrow} p N P+P_{i}
$$

The chromogenic reaction product, pNP turns yellow (absorption at $\lambda \max =405 \mathrm{~nm}$ ) at a $\mathrm{pH}$ of 12 and can be detected using an microtiter plate reader ${ }^{24}$. Due to its $\mathrm{pH}$ dependent activity this enzyme is a good choice to demonstrate a controlled, light induced $\mathrm{pH}$ switching. Optical control of the $\mathrm{pH}$ can be achieved by using reversible photoacids ${ }^{25-27}$ to induce a reversible $\mathrm{pH}$ jump. A photoacid is an aromatic alcohol that transforms into a strong acid upon irradiation ${ }^{28}$ and undergoes ESPT in this process ${ }^{13,29,30}$. The acidity enhancement after excitation is typically on a scale of a factor of $10^{6}-10^{8}$ thus decreasing the $p K_{a}$ by $6-8$ units $^{31}$. One important challenge is the solubility of photoacids in aqueous solvents to be useful in typical biochemical reactions. With the work presented here, we demonstrate a reversible control of an enzymatic reaction using a novel system based on a reversible photoacid.

\section{Results}

Influence of pH and G-acid on Enzyme Kinetics. Acid phosphatase's activity strongly depends on the $\mathrm{pH}$, with an activity optimum at a $\mathrm{pH}$ of 5 , whereas at a $\mathrm{pH}$ of 8 the activity is several orders of magnitude lower [for detailed $\mathrm{pH}$ dependent activity of acid phosphatase see Supplementary Information]. At a pH of 12, G-acid slightly absorbs at $405 \mathrm{~nm}$, causing an offset by 0.14 absorption units, but enzymatic activity is not inhibited by G-acid [Supplementary Information, Fig. S1]. All experiments were conducted using a high $(0.21 \mathrm{U} / \mathrm{ml})$ and a low $(0.12 \mathrm{U} / \mathrm{ml})$ enzyme concentration. Enzymatic activity was not found to be inhibited by G-acid in the concentration of up to $700 \mu \mathrm{M}$. After verification that G-acid has no inhibitory effect on acid phosphatase the citrate buffer was replaced by HPLC water, making G-acid the main buffering component. This maximizes the effect of the protons generated by the photoacid upon excitation.

Illumination assay. Before illumination assays were performed, potential enzyme inhibition by illumination with $3 \mathrm{~W}, 365 \mathrm{~nm}$ high power LEDs was tested in a standard assay, by illuminating the sample. Samples were incubated at a $\mathrm{pH}$ of 5 in citric acid buffer under conditions identical to the light-controlled experiments. UV light did not affect the enzyme's activity [Supplementary Information, Fig. S2]. Two different illumination protocols were conducted to demonstrate the reversible control. (1) Continuous illumination assay: Samples were illuminated for 1-5 minutes and each sample was left in the dark afterwards to an overall incubation time of 10 minutes respectively. (2) Cycled illumination assay: Samples were illuminated for 1-5 minutes switching the light on and off alternatingly. Two different cycled assays were performed: One with one minute switching time and 


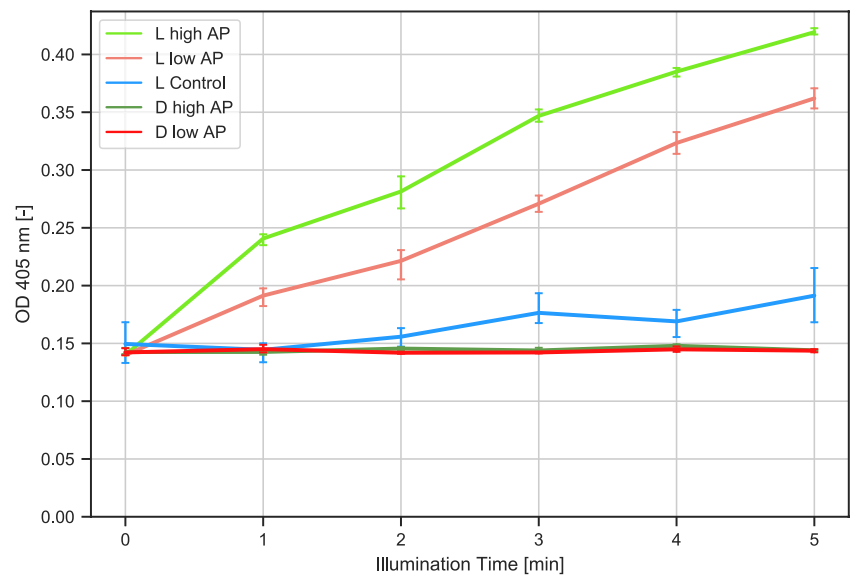

Figure 2. Absorption at $405 \mathrm{~nm}$ vs. light exposure times $1-5 \mathrm{~min}$ at $365 \mathrm{~nm}$. The total incubation time for all samples is 10 minutes, only illumination time varies from $1-5 \mathrm{~min}$. Enzyme concentrations were $0.12 \mathrm{U} / \mathrm{ml}$ (low AP), $0.21 \mathrm{U} / \mathrm{ml}$ (high AP) and a control without enzyme containing G-acid and pNPP only (Control). L indicates light; D indicates absence of illumination (darkness).

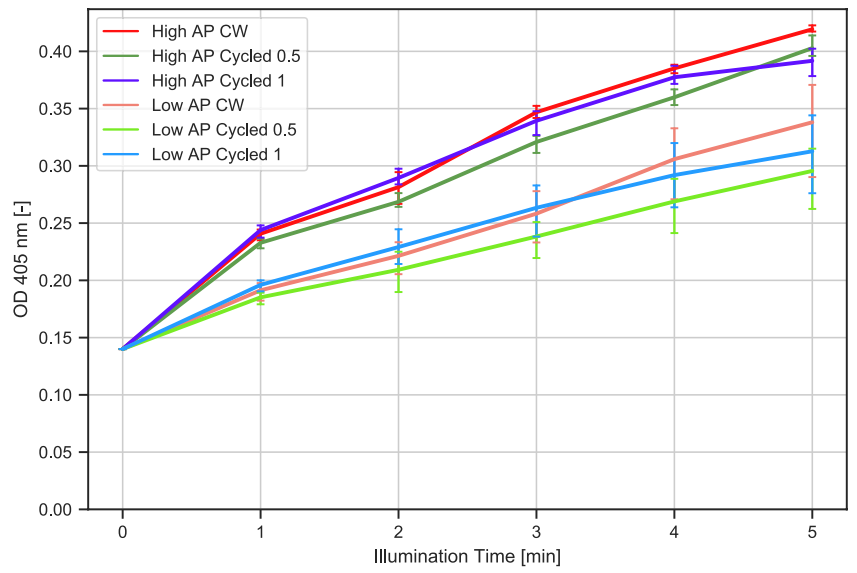

Figure 3. Comparison between continuous light vs. cycled light exposure times. Absorption was measured at $405 \mathrm{~nm}$, exposure was at $365 \mathrm{~nm}$ from 1-5 minutes with an total incubation time of $10 \mathrm{~min}$ for all samples. Enzyme concentrations were $0.12 \mathrm{U} / \mathrm{ml}$ (low AP) or $0.21 \mathrm{U} / \mathrm{ml}$ (high AP). $\mathrm{CW}=$ continuous illumination; Cycled 0.5 and Cycled 1 indicates intervals of 30 seconds and $1 \mathrm{~min}$.

another with 30 seconds switching time and hence twice the number of switches in a given interval. All samples were left in the dark after illumination to an overall incubation time of 10 minutes and had the same cumulative $365 \mathrm{~nm}$ UV light exposure time. Samples without illumination were incubated for 1-10 minutes in a standard assay [Supplementary Information, Standard assay]. The first experiments were conducted under continuous illumination lasting for 1-5 minutes (Fig. 2). The total incubation time for all samples was 10 minutes, differing in light exposure time only.

Acid phosphatase was not found to be active at a $\mathrm{pH}$ of 8 in darkness for both enzyme concentrations. A slight rise in absorption due to UV irradiation in absence of enzyme is recorded, indicating a decay of the substrate pNPP due to light exposure. Values obtained from samples comprising G-acid exposed to UV light correlate well with applied enzyme concentrations. In another setup we illuminated the samples in cycles with intervals of one minute and 30 seconds in direct comparison with continuous illumination (Fig. 3).

Exposure times for all three illumination setups resulted in very similar enzyme activities. As the common factor is the total illumination time, it can be safely concluded that the acid phosphatase remains active even under changing $\mathrm{pH}$ conditions and that the enzymatic reaction can be reversibly controlled in a rapid and stringent manner.

\section{Discussion}

In our experiments we could demonstrate that the activity of acid phosphatase was light-dependent only in the presence of the optical transducer G-acid. The activity measured by pNPP correlated with the amount of enzyme used with low error margins (Fig. 2). In addition, the amount of product formation clearly corresponded to the duration of the illumination time and not total incubation time that included the dark phase. Most importantly, 
the product formation remained strongly dependent on the total illumination time even if intermediate switching with intermediate dark phases was performed (Fig. 3). The same also applies to the two different cycling speeds applied in our experiments. Therefore, it is clear that the enzymatic activity measured in our experiments is controlled by illumination and reversibly transduced by $\mathrm{G}$-acid by changing the $\mathrm{pH}$ in the reaction. We concede that a major drawback of this experimental setup is that the exact $\mathrm{pH}$ cannot be determined online. Yet, many $\mathrm{pH}$-indicators, such as fluorescein or other fluorescent dyes undergo photobleaching ${ }^{32-34}$. We have therefore concluded that an online absorption or fluorescence-based assay is difficult to establish as longer illumination time is required for our experimental setup. Furthermore, we have found that additional dyes will most likely interfere with the spectrum used for excitation and/or substrate turnover detection. Small sample volumes of $100 \mu \mathrm{l}$ typical for biochemical reactions are not compatible with standard $\mathrm{pH}$ electrodes. We have experienced that ISFET-based $\mathrm{pH}$ electrodes, although suitable for small volumes and rapid measurements are very light sensitive, thus giving erroneous readings under illumination. Using a micro- $\mathrm{pH}$ glass electrode would be generally possible, however those have a relatively long response time ${ }^{35}$. Although not directly comparable, we have therefore resorted to estimate the achieved $\mathrm{pH}$ by comparison with enzyme kinetic recorded at different defined $\mathrm{pH}$ values for low and high enzyme concentrations [Supplementary Information, Figs S3 and S4 Acid Phosphatase (0.21 U/ $\mathrm{ml})+100 \mu \mathrm{M} \mathrm{pNPP}+700 \mu \mathrm{M}$ G-acid incubated in $45 \mathrm{mM}$ citrate acid buffer at $\mathrm{pH}$ values from $4-8]$. The reaction $\mathrm{pH}$ for the illumination assays is comparable to a reaction conducted at $\mathrm{pH} 6.5$ using citric acid as a buffer. Thus the $\mathrm{pH}$ in solution is likely lowered by at least $1.5 \mathrm{pH}$ units. In order to achieve a significant photo-induced $\mathrm{pH}$ change by $\mathrm{G}$-acid, residual buffering components had to be reduced to a minimum to avoid proton scavenging. The feasible photo-induced $\mathrm{pH}$ jump depends on the specific composition of the system. More specifically, pNPP has a $p K_{a}=7 \cdot 1^{36}$. Hence, to minimize buffering effect of pNPP we only used $100 \mu \mathrm{M}$, partially resulting in substrate limitation in the standard assay. Future integration of a dedicated online $\mathrm{pH}$ measurement could further be used to finetune the optical pH control by a feed-back mechanism In addition, the enzyme itself may comprise buffering groups and is usually supplied in a stock solution with buffering components for storage. Therefore, it is recommended to obtain enzymes at high stock concentrations in order to avoid carry-over of larger buffer quantities from the stock solution. [Supplementary Information, Figs S5 and S6]. To achieve a maximum excitation of G-acid, components have to be chosen carefully, compromising between detection of enzymatic activity by absorption and managing a sufficient, photo-induced $\mathrm{pH}$ jump. As most commercially available LEDs do not readily emit light at the optimum excitation wavelength of G-acid at $347 \mathrm{~nm}$, we resorted to less optimal but comparably inexpensive LEDs emitting at $365 \mathrm{~nm}$. Generally, other components present in the experimental setup must not absorb strongly at the applied excitation wavelength of G-acid. The photo-induced $\mathrm{pH}$ jump can be further optimized by using a photoacid with a larger $\Delta \mathrm{pH}$, one group of photoacids with a significantly large $\Delta \mathrm{pH}$ is called "Super photoacids"13,37,38 and could be potentially applied. To facilitate the photoacid's excitation, e.g. by using LEDs, it is preferable if the photoacid's absorption is in the visible region. By using nano- LEDs or lasers as an excitation source the whole setup can be further optimized and miniaturized. In addition, digital micromirror devices (DMD) can be used to selectively and simultaneously control illumination of individual pixels in vast arrays. Both enzyme and G-acid exhibited a high robustness in our illumination experiments and remained active, irrespective of the number of applied light switching cycles. Early manual implementations of the described assays have resulted in strong variations due to heat emanating from LEDs and less reproducible arrangement of the samples. As most commercially available LEDs do not readily emit light at the optimum excitation wavelength of G-acid at $347 \mathrm{~nm}$, we resorted to less optimal but comparably inexpensive LEDs emitting at $365 \mathrm{~nm}$. Temperature rises by circa $4{ }^{\circ} \mathrm{C}$ when being illuminated for 5 minutes in this setup, which should be considered as some enzymatic reactions strongly depend on temperature [Supplementary information Fig. S7 for detailed temperature monitoring]. Finally, our self-constructed high power LED standard microtiter 96 well array $^{39}$ was found to be suitable for conducting the photoswitching experiments, by ensuring high reproducibility and low error margins. Other examples for interesting enzymes with a $\mathrm{pH}$ dependent activity could be Laccase, Catalase or Polyphenol Oxidase ${ }^{10}$.

\section{Conclusion}

In this seminal study we could demonstrate the feasibility of a light-induced, reversible control of the enzymatic activity of acid phosphatase in a novel non-invasive manner. The main advantage of optical vs. thermal control of biochemical reactions is the rapid manner by which conditions can be changed and the highly precise spatial resolution that can be achieved without complex hardware and comparably low energy consumption. Reversible photoacids thus offer a new way to transduce this localized $\mathrm{pH}$ control, making them highly attractive for miniaturizable, non-invasive and time-resolved control of biochemical reactions, especially in highly parallelized and combinatorial settings such as arrays, microfluidics and emulsions. We propose that reversible photoacids thus have a yet unexplored potential to be used in high throughput applications and automation. We also demonstrated the feasibility to control reversible photoacids using commercially available LEDs, making their application in highly integrated devices and instruments more attractive.

\section{Materials and Methods}

All experiments were conducted at $40{ }^{\circ} \mathrm{C}$ in black 96 well microtiter plate plates with transparent flat bottom (BRAND GMBH + CO KG, Wertheim, Germany) in triplicates. All data generated or analyzed during this study are included in this published article (and its Supplementary Information files).

Absorption of compounds. Absorption spectra were recorded with the Tecan Infinite ${ }^{\circledR} 200$ PRO multimode plate reader. Dilutions of G-acid (Carbosynth Ltd, Compton, UK) and all other components were performed in $45 \mathrm{mM}$ TRIS-HCL buffer (Roth $\mathrm{GmbH}+\mathrm{Co}$. KG, Karlsruhe, Germany) at a pH of 8 . For detailed absorbance spectra at a $\mathrm{pH}$ of 8 , which was the starting $\mathrm{pH}$ for all illumination assays, see Supplementary Information, 
Fig. S6. General chemicals used in the laboratory were bought from Sigma Aldrich (Taufkirchen, Germany). TCI Chemicals (USA) or Carl Roth GmbH + Co. KG (Karlsruhe, Germany) with the purity grade "for analysis".

Enzyme kinetics at different $\mathrm{pH}$ values. Acid phosphatase from potato (EC 3.1.3.2) was purchased from Sigma Aldrich (Germany) as lyophilized powder with $3.6 \mathrm{U} / \mathrm{mg}$ solid and was stored at $-20^{\circ} \mathrm{C}$. For each experiment acid phosphatase was prepared freshly in cold HPLC grade water (Carl Roth GmbH + Co. KG, Karlsruhe, Germany), as recommended by supplier. Stock concentration was $30 \mathrm{u} / \mathrm{ml}$, this was further diluted to the enzyme concentration needed for the experiment. All experiments were conducted at $40^{\circ} \mathrm{C}$. Acid phosphatases dephosphorylate phosphate groups from phosphate esters under acid conditions. Standard assay was conducted with $100 \mu \mathrm{M}$ pNPP, and a low and a high acid phosphatase concentration respectively. Low acid phosphatase concentration was $0.12 \mathrm{U} / \mathrm{ml}$ and high acid phosphatase concentration was $0.21 \mathrm{U} / \mathrm{ml}$. Experiments were conducted in $45 \mathrm{mM}$ citrate acid buffer with a $\mathrm{pH}$ ranging from 4-6.5. All experiments were conducted with $100 \mu \mathrm{l}$ per well at $40^{\circ} \mathrm{C}$ and stopped with $100 \mu \mathrm{l} 3 \mathrm{M} \mathrm{NaOH}$ after the incubation time, resulting in an overall volume of $200 \mu \mathrm{l}$ per well. For blank, enzyme was added after $100 \mu 13 \mathrm{M} \mathrm{NaOH}$. Samples were incubated for 1-10 mins and stopped each minute. To test potential inhibition of G-acid on the enzyme an assay was conducted with $100 \mu \mathrm{M}$ pNPP, $700 \mu \mathrm{M}$ G-acid and low and high AP concentration respectively. Experiments were conducted in $45 \mathrm{mM}$ citrate acid buffer with a $\mathrm{pH}$ from 4-6.5. All experiments were conducted with $100 \mu \mathrm{l}$ per well and stopped with $100 \mu \mathrm{l}$ $3 \mathrm{M} \mathrm{NaOH}$ after the incubation time, resulting in an overall volume of $200 \mu \mathrm{l}$ per well. For blank, enzyme was added after $100 \mu \mathrm{l} 3 \mathrm{M} \mathrm{NaOH}$. Samples were incubated for 1-10 mins and stopped each minute. Sample absorbance was measured using a plate reader Infinite $200 \mathrm{PRO}^{\circledR}$ (Tecan, Männedorf, Switzerland).

Illumination assay. For illumination assays, a self-constructed device with $3 \mathrm{~W}$ high power $365 \mathrm{~nm}$ LEDs, suitable for a 96 well microtiter plate, was used. Standard assay contained $700 \mu \mathrm{M} \mathrm{G}$-acid, low $(0.12 \mathrm{U} / \mathrm{ml})$ or high $(0.21 \mathrm{U} / \mathrm{ml})$ enzyme concentration and $100 \mu \mathrm{M}$ pNPP. Reaction in $45 \mathrm{mM} \mathrm{pH} 5$ citric acid buffer was stopped using $100 \mu \mathrm{l} 3 \mathrm{M} \mathrm{NaOH}$, resulting in a final volume of $200 \mu \mathrm{l}$. After the reaction was stopped with $100 \mu \mathrm{l} 3 \mathrm{M}$ $\mathrm{NaOH}, \mathrm{pH}$ was measured to be 12 for all assays. All samples were incubated at $40{ }^{\circ} \mathrm{C}$ and experiments were conducted in triplicates. Error bars are included in all diagrams.

\section{References}

1. Bautista-Barrufet, A. et al. Optical control of enzyme enantioselectivity in solid phase. ACS Catal. 4, 1004-1009, https://doi. org/10.1021/cs401115s (2014).

2. Zhou, X. X., Chung, H. K., Lam, A. J. \& Lin, M. Z. Optical control of protein activity by fluorescent protein domains. Science 338, 810-814, https://doi.org/10.1126/science.1226854 https://science.sciencemag.org/content/338/6108/810.full.pdf (2012).

3. Krauss, U., Drepper, T. \& Jaeger, K.-E. Enlightened enzymes: Strategies to create novel photoresponsive proteins. Chem. Eur. J. 17, 2552-2560, https://doi.org/10.1002/chem.201002716 (2019).

4. Cueto, M. et al. Platinum nanoparticles as photoactive substrates for mass spectrometry and spectroscopy sensors. The J. Phys. Chem. C 118, 11432-11439, https://doi.org/10.1021/jp500190m (2014)

5. Sundhoro, M. et al. Fabrication of carbohydrate microarrays on a poly(2-hydroxyethyl methacrylate)-based photoactive substrate. Org. Biomol. Chem. 14, 1124-1130, https://doi.org/10.1039/C5OB01417D (2016).

6. Klàn, P. et al. Photoremovable protecting groups in chemistry and biology: Reaction mechanisms and efficacy. Chem. Rev. 113, 119-191, https://doi.org/10.1021/cr300177k (2013).

7. Bochet, C. G. Photolabile protecting groups and linkers. J. Chem. Soc., Perkin Trans. 1(1), 125-142, https://doi.org/10.1039/ B009522M (2013).

8. Reisinger, B. et al. Exploiting protein symmetry to design light-controllable enzyme inhibitors. Angew. Chem. Int. Ed. 53, 595-598, https://doi.org/10.1002/anie.201307207 (2019).

9. Lloyd, J. B. \& Mason, R. W. Biology of the Lysosome, vol. 416 pp (Plenum Press, 1996).

10. Kohse, S., Neubauer, A., Pazidis, A., Lochbrunner, S. \& Kragl, U. Photoswitching of enzyme activity by laser-induced ph-jump. J. Am. Chem. Soc. 135(25), 9407-9411, https://doi.org/10.1021/ja400700x (2013).

11. Author Index available at https://onlinelibrary.wiley.com/doi/10.1002/0470857277.indauth, https://doi.org/10.1002/0470857277 (Accessed on 2019, t. M. The chemistry of phenols (John Wiley and Sons, 2003)

12. Warshel, A. Picosecond studies of excited-state protonation and deprotonation kinetics. the laser ph jump. J. Am. Chem. Soc. 101(3), 746-748, https://doi.org/10.1007/978-3-642-67099-2-61 (1979).

13. Tolbert, L. M. \& Solntsev, K. M. Excited-state proton transfer: From constrained systems to super photoacids to superfast proton transfer. Accounts Chem. Res. 35, 19-27, https://doi.org/10.1021/ar990109f (2002).

14. Gajst, O., Pinto da Silva, L., Esteves da Silva, J. C. G. \& Huppert, D. Excited-state proton transfer from the photoacid 2-naphthol-8sulfonate to acetonitrile/water mixtures. The J. Phys. Chem. A 122, 6166-6175, https://doi.org/10.1021/acs.jpca.8b04417 (2018).

15. Premont-Schwarz, M. Elementary solute-solvent interactions and the photophysical properties of photoacids. Ph.D. thesis, Humboldt-Universität zu Berlin, Mathematisch-Naturwissenschaftliche Fakultät I (2013).

16. Gutman, M., Huppert, D. \& Pines, E. The ph jump: a rapid modulation of ph of aqueous solutions by a laser pulse. J. Am. Chem. Soc. 103, 3709-3713, https://doi.org/10.1021/ja00403a016 (1981).

17. Gutman, M., Nachliel, E., Gershon, E., Giniger, R. \& Pines, E. ph jump: Kinetic analysis and determination of the difussioncontrolled rate constants. J. Am. Chem. Soc. 105(8), 2210-2216, https://doi.org/10.1002/kin.550050503 (1983).

18. Kagel, H., Glökler, J. \& Frohme, M. Photoacids in biochemical applications. J. Cell. Biotechnol. 4, 23-30, https://doi.org/10.3233/ JCB-189004 (2018)

19. Khanh, T. Q., Bodrogi, P., Vinh, T. Q. \& Winkler, H. LED Lighting: Technology and Perception, https://doi.org/10.1002/9783527670147 (Wiley VCH Verlag GmbH \& Co. KGaA, Weinheim, Germany, 2014)

20. Anand, A. \& Kumar Srivastava, P. A molecular description of acid phosphatase. Appl. biochemistry biotechnology 167, 2174-97, https://doi.org/10.1007/s12010-012-9694-8 (2012).

21. Fernley, H. N. \& Walker, P. G. Studies on alkaline phosphatase. inhibition by phosphate derivatives and the substrate specificity. The Biochem. J. 104, 1011-8, https://doi.org/10.1042/bj1041011v.

22. Gellatly, K. S., Moorhead, G. B. G., Duff, S. M. G., Lefebvre, D. D. \& Plaxton, W. C. Purification and characterization of a potato tuber acid phosphatase having significant phosphotyrosine phosphatase activity. Plant physiology 106, 223-232 [PMCID: PMC159520 PMID: 12232323] (1994).

23. Waymack, P. P. \& Etten, R. L. V. Isolation and characterization of a homogeneous isoenzyme of wheat germ acid phosphatase. Arch. Biochem. Biophys. 288, 621-633, https://doi.org/10.1016/0003-9861(91)90245-E (1991). 
24. Bergmeyer, H., Gawehn, K. \& Grassl, M. Methods of Enzymatic Analysis, https://doi.org/10.1016/B978-0-12-091302-2.X5001-4 (1974).

25. Tran-Thi, G., Prayer, P. \& Hynes Primary ultrafast events preceding the photoinduced proton transfer from pyranine to water. Chem. Phys. Lett. 329, 421-430, https://doi.org/10.1016/S0009-2614(00)01037-X (2000).

26. Amdursky, N., Simkovitch, R. \& Huppert, D. Excited-state proton transfer of photoacids adsorbed on biomaterials. The J. Phys. Chem. B 118, 13859-13869, https://doi.org/10.1021/jp509153r PMID: 25380297 (2014).

27. Amdursky, N., Rashid, M. H., Stevens, M. M. \& Yarovsky, I. Exploring the binding sites and proton diffusion on insulin amyloid fibril surfaces by naphthol-based photoacid fluorescence and molecular simulations. Sci. Reports 7, 6245, https://doi.org/10.1038/ s41598-017-06030-4 (2017).

28. Liao, Y. Design and applications of metastable-state photoacids. Accounts Chem. Res. 50, 1956-1964, https://doi.org/10.1021/acs. accounts.7b00190 (2017).

29. Barroso, M., Arnaut, L. G. \& Formosinho, S. J. Intersecting-state model calculations on fast and ultrafst excited-state proton transfers in naphthols and subsitiuted naphthols. J. Photochem. Photobiol. 154(1), 13-21, https://doi.org/10.1016/S1010-6030(02)00261-7 (2002).

30. Arnaut, L. G. \& Formosinho, S. J. Excited-state proton transfer reations i. fundamentals and intermolecular reactions. J. Photochem. Photobiol. A: Chem. 75(1), 1-20, https://doi.org/10.1016/1010-6030(93)80157-5 (1993).

31. Rini, M. Femtosecond mid-Infrared spectroscopy of elementary photoinduced reactions. Ph.D. thesis, Humboldt-Universität zu Berlin, Mathematisch-Naturwissenschaftliche Fakultät I (2003).

32. Berglund, A. J. Nonexponential statistics of fluorescence photobleaching. The J. Chem. Phys. 121(7), 2899-903, https://doi. org/10.1063/1.1773162 (2004).

33. Ghauharali \& Brakenhoff Fluorescence photobleaching based image standardization for fluorescence microscopy. J. Microsc. 198, 88-100, https://doi.org/10.1046/j.1365-2818.2000.00683 (2001).

34. Song, L., Hennink, E. J., Young, I. T. \& Tanke, H. J. Photobleaching kinetics of fluorescein in quantitative fluorescence microscopy. Biophys. journal 68, 2588-600, https://doi.org/10.1016/S0006-3495(95)80442-X (1995).

35. Artiola, J. 13 - environmental chemical properties and processes. In Artiola, J. F., Pepper, I. L. \& Brusseau, M. L. (eds) Environmental Monitoring and Characterization, 241-261, https://doi.org/10.1016/B978-012064477-3/50015-1 (Academic Press, Burlington, 2004).

36. Denu, J. M., Lohse, D. L., Vijayalaksmi, J., Saper, M. A. \& Dixon, J. E. Visualization of intermediate and transition-state structures in protein-tyrosine phosphatase catalysis. Proc. Natl. Acad. Sci. 93(6), 2493-8, https://doi.org/10.1073/pnas.93.6.2493 (1996).

37. Solntsev, K., Huppert, D. \& Agmon, N. Photochemistry of "super"-photoacids. solvent effects. J. Phys. Chem. A 103, 6984-6997, https://doi.org/10.1021/jp9902295 (1999).

38. Knochenmuss, R., Solntsev, K. M. \& Tolbert, L. M. Molecular beam studies of the "super" photoacid 5-cyano-2-naphthol in solvent clusters. The J. Phys. Chem. 105(26), 6393-6401, https://doi.org/10.1021/jp010011u (2001).

39. Kagel, H., Jacobs, H., Glökler, J. \& Frohme, M. A novel microtiter plate format high power open source led array. Photonics 6(1), 17, https://doi.org/10.3390/photonics6010017 (2019).

\section{Acknowledgements}

The authors acknowledge the financial support by the "Europäischer Fonds für regionale Entwicklung" (EFRE) and the Investitionsbank des Landes Brandenburg (ILB); StAFF project 85000780.

\section{Author Contributions}

H.K. performed the experiments, analyzed the data and drafted the manuscript. F.F.B. supervised the research, M.F. is supervisor and corresponding author of the manuscript. J.F.G. supervised the study and finalized the manuscript as senior author. All authors reviewed the manuscript.

\section{Additional Information}

Supplementary information accompanies this paper at https:/doi.org/10.1038/s41598-019-50867-w.

Competing Interests: The authors declare no competing interests.

Publisher's note Springer Nature remains neutral with regard to jurisdictional claims in published maps and institutional affiliations.

Open Access This article is licensed under a Creative Commons Attribution 4.0 International License, which permits use, sharing, adaptation, distribution and reproduction in any medium or format, as long as you give appropriate credit to the original author(s) and the source, provide a link to the Creative Commons license, and indicate if changes were made. The images or other third party material in this article are included in the article's Creative Commons license, unless indicated otherwise in a credit line to the material. If material is not included in the article's Creative Commons license and your intended use is not permitted by statutory regulation or exceeds the permitted use, you will need to obtain permission directly from the copyright holder. To view a copy of this license, visit http://creativecommons.org/licenses/by/4.0/.

(c) The Author(s) 2019 